ORIGINAL ARTICLE

\title{
Unsupervised firearm handling by California adolescents
}

\author{
M Miller, D Hemenway
}

Injury Prevention 2004;10:163-168. doi: 10.1136/ip.2004.005447

\begin{abstract}
Objective: Relatively little is known about the behavior of adolescents around firearms. The present investigation was undertaken to estimate the proportion of community-residing adolescents who report that they have ever handled a gun without adult knowledge or supervision.

Methods: A random digit dial interview was conducted with 5801 California adolescents as part of the California Health Interview Survey. Respondents were asked whether they have ever held a gun and whether they have ever done so without adult knowledge or supervision. Study design and population weights were applied to these data. In addition, adolescents' reports about the most recent unsupervised handling incident were coded to ascertain what they were doing with the gun as well as with whom and where the incident occurred. Results: One third (33\%) of California adolescents report that they have handled a firearm; $5 \%$ report that they have done so without adult knowledge or supervision. Half $(49 \%)$ of all unsupervised handling involved shooting and only $11 \%$ occurred in the respondent's home. Several demographic variables (being male, African American, living in a rural area) and risk behaviors (smoking, drinking, being the victim of a gun related threat), as well as having a gun in the home and parents not knowing the adolescent's whereabouts in the afternoon were each associated with unsupervised gun handling.

Conclusions: Unsupervised gun handling is associated with other health risk behaviors. Unsupervised gun handling typically involves shooting the gun and usually occurs with friends, away from the home.
\end{abstract}

\section{See end of article for authors' affiliations \\ Correspondence to: Dr Matthew Miller, Harvard School of Public Health, 677 Huntington Avenue, Boston, MA 01115 , USA; mmiller@ hsph.harvard.edu} he..............
M ore American adolescents die from firearm injuries than from any other cause except motor vehicle crashes. ${ }^{1}$ In the year 2000, 1716 of those aged 10 to 19 years died from firearm homicide (accounting for over three fourths of adolescent homicides), 1007 from firearm suicide (accounting for more than half of adolescent suicides), and an additional 156 died from unintentional gunfire. The threat to adolescent health extends beyond fatalities: for every fatal firearm injury there are another four to five non-fatal hospital treated gunshot injuries. ${ }^{23}$

Several case-control and ecologic studies suggest that household firearm ownership is a strong risk factor for suicide, ${ }^{4-18}$ homicide, ${ }^{1}{ }^{10} 18-27$ and unintentional firearm death $^{28} 29$ and that most guns involved in self inflicted and unintentional firearm injuries among adolescents originate either from the victim's home or the home of a friend or relative. ${ }^{30}$ In addition, the relative risk of suicide associated with a gun in the home appears to be higher for adolescents than for any other age group, ${ }^{9}$ especially those without a history of depression or other mental illness. ${ }^{6}$

Despite adolescent's relative ease of access to firearms in the United States-25\% of American adolescents report having easy access to a gun in the home $e^{31}$ and approximately $6 \%$ of high school students report that they carried a firearm at least once over the 30 days preceding the survey ${ }^{32}$ - there is little empirical research on adolescent exposure to and behavior around firearms. What has been observed about children's exposure to firearms has come from studies on younger children, ${ }^{33-35}$ or has used specialized samples such as high school students ${ }^{31}{ }^{36-46}$ or incarcerated youth ${ }^{47-50}$ from a single, often urban, locale. ${ }^{30} 383945-47$ Furthermore, these studies have focused on behavioral and attitudinal correlates of carrying concealed firearms, ${ }^{41}{ }^{51-53}$ a presumably dangerous activity that usually requires forethought. In this manuscript we report demographic and behavioral correlates of handling a gun without adult knowledge or supervision, potentially a more exploratory behavior.
To our knowledge, the only previous study to describe correlates of unsupervised firearm handling by adolescents ${ }^{54}$ was a school based survey of 12007 th and 10th graders from two large cities (Boston and Milwaukee). In that study $28 \%$ of adolescents reported having ever handled a gun without adult supervision or knowledge and $17 \%$ reported having ever carried a concealed gun. Correlates of unsupervised gun handling included male gender, older age, living in a household with a firearm, smoking, binge drinking, and exposure to gun violence such as having had a family member shot or living in a neighborhood with frequent shootings. Contextual information about actual handling behavior was not elicited. Our study extends these findings and adds new information about firearm related experiences of adolescents by providing verbatim descriptions of the most recent episode of unsupervised firearm handling, and by analyzing a much larger sample (5801) selected to represent a cross section of all adolescents living in California.

\section{METHODS}

The California Health Interview Survey (CHIS) is the largest health survey of its kind in the nation. The data come from a random digit dial telephone survey of adults, adolescents, and children. Information for the present study was gathered as a supplement to the adolescent survey. The detailed methodology for the CHIS is available in a series of five reports. ${ }^{55}$

The CHIS sample comes from the population of all households in California with a telephone number. The sample was classified into 41 strata: 33 comprised counties of more than 100000 people; groupings of the remaining less populous counties comprised the other eight strata. A sample from each stratum was selected using a computer generated list of all (list and unlisted) telephone numbers. In each household selected, one adult was randomly selected to be interviewed.

If an adolescent lived in the household, the adult (parent or guardian) was asked for verbal consent to allow the 
adolescent to be interviewed. Consent was then requested from the adolescent. If more than one adolescent resided in a household, one was selected at random. Among adults with an adolescent, $75 \%$ allowed that adolescent to be interviewed. Of those adolescents, $84 \%$ agreed to be interviewed, leading to a response rate of $63 \%$. However, given the dual layer of permission, if we include an estimate of households that were called but no adult was reached (for example, surveyors only reached an answering machine) and adults who were reached but refused to be interviewed, the overall response rate falls to $24 \%$.

CHIS collected data from 5801 adolescents, who were interviewed between November 2000 and October 2001. Interviews were conducted in English, Spanish, Mandarin, Cantonese, Vietnamese, Korean, and Cambodian (Khmer). About 9\% of adolescents were interviewed in a language other than English.

Adolescents were asked a series of gun questions, including "Have you ever held a gun in your own hand?" and for those answering in the affirmative "Have you ever handled a gun without either adult supervision or knowledge?". Respondents answering in the affirmative to both questions were asked to describe "the most recent gun use without adult supervision or knowledge". For brevity we label this "unsupervised handling". Gun type was not specified.

After reading the responses, the authors created three classification schemes. The first taxonomy ("doing what with the gun") consisted of seven mutually exclusive categories describing the activity engaged in at the time of the most recent episode of unsupervised handling. These were (1) shooting (for example, hunting, target practice), (2) looking at/holding, (3) cleaning, (4) using the firearm in self defense, (5) unintentionally firing the gun, (6) miscellaneous activities, and (7) insufficient information provided. For simplicity we assume that hunting involved shooting. The second taxonomy ("with whom") was based on whether the respondent was alone or with others during the last unsupervised handling. The five mutually exclusive categories were: (1) alone, (2) with friends, (3) with relatives, (4) a miscellaneous category, and (5) insufficient information provided. The third taxonomy ("where") was based on where the most recent episode of unsupervised handling occurred and had six mutually exclusive categories: (1) respondent's home, (2) friend's home, (3) relative's home, (4) outdoor area such as a hunting area/shooting range, (5) a miscellaneous category, and (6) insufficient information provided. A research assistant and one of the authors (MM) separately read and categorized responses to the open ended questions and then met and reached agreement on the classification of each. If the verbatim account suggested that incident occurred in the presence of an adult the respondent was not counted as a case of handling without adult knowledge or supervision (three potential cases eliminated). Of the 321 adolescents who reported unsupervised firearm handling, specific verbatim responses could be categorized for 234 adolescents for the "doing what with the gun" question, 160 adolescents for the "with whom" question, and 182 adolescents for the "where" question.

We examined 14 potential correlates of firearm handling. Two variables, urban/rural and income (above three times the poverty index or not), came from the adult questionnaire. Twelve correlates came from responses of the adolescents and can be grouped into demographic characteristics and risk behaviors:

Demographic characteristics: (1) gender; (2) age (12-13; 1415; 16-17); (3) race/ethnicity (Hispanic/non-Hispanic White/ non-Hispanic Asian/non-Hispanic Black/non-Hispanic other); (4) citizenship (United States citizen or not); (5) living in a home with one compared with two or more adults.
Potential risks: (6) firearm in the home ("Do any members of your household happen to keep a firearm at home? It could be kept in your home, garage, outdoor storage area, car, truck or other motor vehicle?"); (7) cigarette smoker ("Have you ever smoked cigarettes regularly, that is, at least one cigarette everyday for 30 days?"); (8) binge drinker, drinker but not a binge drinker or not a drinker ("If we consider one drink to be a can or bottle of beer, a glass of wine, a shot of liquor, or one mixed drink...How many days in the past 30 days did you have five or more drinks in one day?"-any response greater than zero is categorized as a binge drinker-and "Have you ever had more than a few sips of any alcoholic beverage like wine, beer, mixed drinks or liquor?"); (9) victim of a gun threat ("Has anyone ever brought out, shown, or used a gun against you in a threatening way)"; (10) recent serious injury ("Have you been injured seriously within the last 12 months-got medical attention or advice"); (11) attending school (yes; no); and (12) parental involvement ("How much do your parents (or guardians) really know about where you are most afternoons? Would you say they know a lot, a little or nothing?"').

We used bivariate $\chi^{2}$ analyses and multivariate logistic regression analysis to identify patterns in the data. CHIS uses a sophisticated weighting scheme to account for a wide variety of factors, described in detail elsewhere, ${ }^{56}$ including multiple telephone lines (these households were more likely to be contacted), a listed address (these households were more likely to have received an advance letter), and oversampling of rural areas and certain ethnic groups. Percentages from the three descriptive taxonomies (table 3 ) are not weighted. All other analyses and percentages are weighted (tables 1 and 2). Weighted findings can be considered to provide a reasonable approximation of the population of adolescents in California.

The Harvard School of Public Health's Institution Review Board gave this study an exempt status.

\section{RESULTS}

Among the adolescents surveyed, 13 chose not to answer the questions about gun handling. Approximately 33\% reported ever handling a gun, and 5\% said they had handled a gun without adult supervision or knowledge (table 1).

Adolescents who reported handling a firearm without adult supervision or knowledge were disproportionately from rural areas: $14 \%$ of the entire cohort are from rural areas compared with $24 \%$ of adolescents who have handled a firearm without adult knowledge or supervision (table 1). Adolescents who reported unsupervised handling were also more likely to live in households with firearms, to report smoking and binge drinking, to have been threatened with a firearm, to have been injured seriously during the previous year, and to have less parental involvement in their lives (table 2). For example, whereas $25 \%$ of smokers reported unsupervised handling, only $3 \%$ of non-smoking respondents reported unsupervised handling; 15\% of binge drinkers reported unsupervised handling compared with only $1 \%$ of non-drinking adolescents. Older age was associated with unsupervised handling in the bivariate but not in multivariate analyses.

Three hundred and thirteen of the 321 adolescents who reported unsupervised handling supplied verbal accounts of the most recent episode. Examples of the six types of activities ("doing what with the gun") are given below:

(1) Shooting (hunting/target practice) ("Three days ago my parents weren't home and I was shooting around"; "Home alone last weekend and went outside and shot one of the rifles"). 
Table 1 Weighted distribution of characteristics for the entire cohort and among those adolescents who report ever handling a firearm without adult knowledge or supervision, 2000-01

\begin{tabular}{|c|c|c|}
\hline & $\begin{array}{l}\text { \% Of entire } \\
\text { cohort }\end{array}$ & $\begin{array}{l}\% \text { Of adolescents who } \\
\text { have handled a } \\
\text { firearm without adult } \\
\text { knowledge or } \\
\text { supervision }\end{array}$ \\
\hline Ever handled a firearm & 33 & 100 \\
\hline $\begin{array}{l}\text { Ever handled a firearm } \\
\text { without adult supervision } \\
\text { or knowledge } \\
\text { Gender }\end{array}$ & 5 & 100 \\
\hline Male & 51 & 82 \\
\hline Female & 49 & 18 \\
\hline \multicolumn{3}{|l|}{ Age (years) } \\
\hline $16-17$ & 33 & 54 \\
\hline $14-15$ & 33 & 34 \\
\hline $12-13$ & 34 & 12 \\
\hline \multicolumn{3}{|l|}{ Race/ethnicity } \\
\hline Non-Hispanic Asian & 8 & 3 \\
\hline Non-Hispanic Black & 5 & 8 \\
\hline Non-Hispanic other & 4 & 5 \\
\hline Hispanic & 39 & 37 \\
\hline Non-Hispanic White & 43 & 47 \\
\hline \multicolumn{3}{|l|}{ Area } \\
\hline Rural & 14 & 24 \\
\hline Urban & 86 & 76 \\
\hline \multicolumn{3}{|l|}{ Poverty level } \\
\hline$<3 \times$ & 57 & 61 \\
\hline$>3 x$ & 43 & 39 \\
\hline \multicolumn{3}{|l|}{ Citizenship } \\
\hline US citizen & 89 & 92 \\
\hline Not a US citizen & 11 & 8 \\
\hline \multicolumn{3}{|l|}{$\begin{array}{l}\text { Number of adults in } \\
\text { household }\end{array}$} \\
\hline 1 & 14 & 19 \\
\hline$>1$ & 86 & 81 \\
\hline \multicolumn{3}{|l|}{$\begin{array}{l}\text { Presence of gun in } \\
\text { household }\end{array}$} \\
\hline Yes & 20 & 36 \\
\hline No & 78 & 61 \\
\hline Refused question & 3 & 3 \\
\hline \multicolumn{3}{|l|}{ Smoker } \\
\hline Yes & 5 & 29 \\
\hline No & 95 & 71 \\
\hline \multicolumn{3}{|l|}{ Drinking habit } \\
\hline Binge drink & 18 & 61 \\
\hline Drink, don't binge & 14 & 18 \\
\hline Don't drink & 68 & 21 \\
\hline \multicolumn{3}{|l|}{ Victim of a gun threat } \\
\hline Yes & 4 & 23 \\
\hline No & 96 & 77 \\
\hline \multicolumn{3}{|l|}{$\begin{array}{l}\text { Injured seriously in last } \\
12 \text { months }\end{array}$} \\
\hline Yes & 14 & 26 \\
\hline No & 86 & 74 \\
\hline \multicolumn{3}{|l|}{ School attendance } \\
\hline No & 2 & 5 \\
\hline Yes & 98 & 95 \\
\hline \multicolumn{3}{|l|}{$\begin{array}{l}\text { Parents know whereabouts } \\
\text { in afternoon }\end{array}$} \\
\hline No & 19 & 39 \\
\hline Yes & 81 & 61 \\
\hline
\end{tabular}

(2) Looking at/holding (“At girlfriend's house picked up her father's gun"; "Happened when was 6 and was visiting a friend whose dad was a policeman and she showed it to me and we were handling it").

(3) Cleaning/maintaining ("Cleaning it and refilling clips and put gun lock on it").

(4) Fired unintentionally ("Was 7 went to grandma's room touched it and it blew").

(5) Self defense ("Someone was in the backyard and got the gun for protection"; "Big dog in grandpa's backyard I
Table 2 Weighted correlates of handling a firearm without adult knowledge or supervision among California adolescents, 2000-01

\begin{tabular}{|c|c|c|}
\hline $\begin{array}{l}\text { Respondent } \\
\text { characteristic }\end{array}$ & $\begin{array}{l}\% \text { Of adolescents } \\
\text { who have ever } \\
\text { handled a firearm } \\
\text { without adult } \\
\text { knowledge or } \\
\text { supervision }\end{array}$ & $\begin{array}{l}\text { Adjusted odds ratio } \\
(95 \% \mathrm{Cl}) \text { for ever } \\
\text { handling a firearm } \\
\text { without adult } \\
\text { knowledge or } \\
\text { supervision }\end{array}$ \\
\hline \multicolumn{3}{|l|}{ Gender } \\
\hline Male & $7^{* * *}$ & $4.2(2.5 \text { to } 7.1)^{\star * *}$ \\
\hline Female & 2 & Reference \\
\hline \multicolumn{3}{|l|}{ Age (years) } \\
\hline $16-17$ & $7^{* * *}$ & $1.2(0.6$ to 2.4$)$ \\
\hline $14-15$ & $5^{\star * *}$ & $1.6(0.8$ to 3.2$)$ \\
\hline $12-13$ & 2 & Reference \\
\hline \multicolumn{3}{|l|}{ Race/ethnicity } \\
\hline Non-Hispanic Asian & $2^{*}$ & $0.8(0.4$ to 2.0$)$ \\
\hline Non-Hispanic Black & 7 & $2.5(1.0 \text { to } 6.2)^{*}$ \\
\hline Non-Hispanic other & 6 & $1.0(0.4$ to 2.5$)$ \\
\hline Hispanic & 4 & $1.2(0.8$ to 1.9$)$ \\
\hline Non-Hispanic White & 5 & Reference \\
\hline \multicolumn{3}{|l|}{ Area } \\
\hline Rural & $8^{* * *}$ & $2.1(1.4 \text { to } 3.2)^{\star \star \star}$ \\
\hline Urban & 4 & Reference \\
\hline \multicolumn{3}{|l|}{ Poverty level } \\
\hline$<3 \times$ & 5 & $1.0(0.7$ to 1.5$)$ \\
\hline$>3 x$ & 4 & Reference \\
\hline \multicolumn{3}{|l|}{ Citizenship } \\
\hline US citizen & 5 & $0.8(0.4$ to 1.9$)$ \\
\hline Not a US citizen & 4 & Reference \\
\hline \multicolumn{3}{|l|}{$\begin{array}{l}\text { Number of adults in } \\
\text { household }\end{array}$} \\
\hline 1 & $6^{*}$ & $1.2(0.8$ to 1.9$)$ \\
\hline$>1$ & 4 & Reference \\
\hline \multicolumn{3}{|l|}{$\begin{array}{l}\text { Presence of gun in } \\
\text { household }\end{array}$} \\
\hline Yes & $8^{* \star *}$ & $2.1(1.5 \text { to } 2.9)^{\star \star *}$ \\
\hline Refused question & 5 & $2.7(0.8$ to 8.6$)$ \\
\hline No (reference) & 4 & Reference \\
\hline \multicolumn{3}{|l|}{ Smoker } \\
\hline Yes & $25^{\star \star *}$ & $2.8(1.7 \text { to } 4.7)^{\star * *}$ \\
\hline No (reference) & 3 & Reference \\
\hline \multicolumn{3}{|l|}{ Drinking habit } \\
\hline Binge drink & $15^{\star \star *}$ & $7.9(4.9 \text { to } 12.9)^{* * *}$ \\
\hline Drink, don't binge & $6^{* * *}$ & $2.9(1.7 \text { to } 4.7)^{\star * *}$ \\
\hline Don'† drink (reference) & 1 & Reference \\
\hline \multicolumn{3}{|c|}{ Victim of a gun threat } \\
\hline Yes & $27^{* \star *}$ & $3.7(2.0 \text { to } 6.8)^{\star \star *}$ \\
\hline No (reference) & 4 & Reference \\
\hline \multicolumn{3}{|l|}{$\begin{array}{l}\text { Injured seriously in last } \\
12 \text { months }\end{array}$} \\
\hline Yes & $8^{* * *}$ & $1.5(1.0$ to 2.5$)$ \\
\hline No (reference) & 4 & Reference \\
\hline \multicolumn{3}{|l|}{ School attendance } \\
\hline No & $11^{*}$ & $1.3(0.4$ to 4.5$)$ \\
\hline Yes (reference) & 4 & Reference \\
\hline \multicolumn{3}{|c|}{$\begin{array}{l}\text { Parents know whereabouts } \\
\text { in afternoon }\end{array}$} \\
\hline No & $9^{* \star *}$ & $1.6(1.2 \text { to } 2.2)^{\star *}$ \\
\hline Yes (reference) & 3 & Reference \\
\hline
\end{tabular}

went after it because it was scarring the kids"; "I was going to get jumped and they had chanks and I had to do something in self-defense I guess").

(6) Miscellaneous ("My friend showed me one and fired it into the floor").

(7) Unclear/not stated ("Nighttime in my backyard").

Excluding the last two categories, the most frequent activities involving unsupervised handling were shooting (that is, hunting or target practice) (49\%) and looking/ holding the gun (39\%) (table 3). In four instances the firearm went off unintentionally and in one case someone was hurt ("summer time accidentally shot friend's arm"). There were 


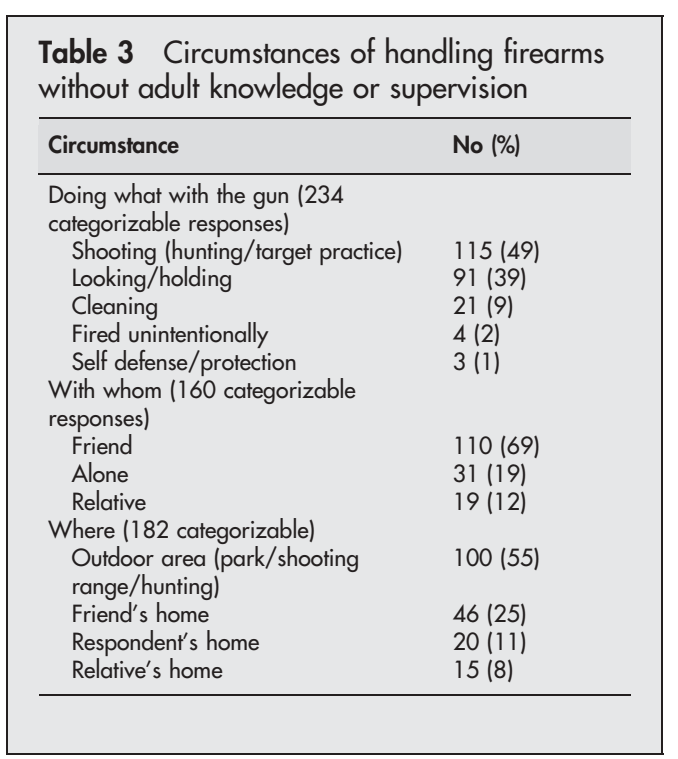

three reports of using the firearm in self defense (all described above). Compared with older adolescents who reported unsupervised handling, 12-13 year olds were more likely to report just looking at the gun or cleaning it (not shown).

The second taxonomy ("with whom") was based on whether the respondent was alone or with others. Examples from each category are given below:

(1) Friends ("About a month ago me and my friends were shooting things like birds and stuff").

(2) Relatives ("Outside uncle's house with cousins target shooting").

(3) Alone ("Last hunting season I cleaned the guns by myself").

(4) Miscellaneous ("Went hunting with ex-fiancée").

(5) Unknown/not defined ("About 4 days ago I went squirrel hunting").

Excluding the last two categories, in most instances of unsupervised handling the adolescent was with someone, a friend $(69 \%)$ or relative $(12 \%)$. Less than one fifth of the time were adolescents alone when they handled without adult supervision or knowledge.

The third classification schema ("where") was based on the location of the incident. Examples include:

(1) Respondent's home ("Dad wasn't home so we went into the bedroom and got the gun"; "Going through father and mother's desk he found it").

(2) Friend's home ("A year ago at my friend's house, you know they're not hard to get around here").

(3) Relative's home ("At a cousin's house holding and pointing a gun").

(4) Hunting/target practice/outdoor area ("Two years ago handled a gun with friends at a park"; "A year ago two of my friend's took me hunting for the first time, there were no adults there").

(5) Unspecified ("Was 7 years old but no bullets in it"; "Someone was trying to sell me a gun"; "I don't remember").

Excluding the last category, most incidents (55\%) occurred in an outdoor area, $36 \%$ in the home of a friend or relative, and $11 \%$ at the respondent's home.

\section{DISCUSSION}

Male gender, living in a gun owning household, smoking, binge drinking, and victim of a gun threat were each associated with unsupervised gun handling. These findings are consistent with those of the only previous study of unsupervised handling among adolescents. ${ }^{54}$ The confluence of high risk behaviors-smoking, binge drinking, unauthorized gun handling-while troubling, is not surprising. For example, other studies have found a connection between heavy drinking and risky firearm behavior. ${ }^{45}$ 57-60

The prevalence of unsupervised handling in the present study ( $5 \%$ overall and $4 \%$ in urban areas) is markedly lower than that reported previously, ${ }^{54}$ where $28 \%$ of youth living in urban Boston and Milwaukee reported unsupervised firearm handling ( $17 \%$ of whom report also carrying a concealed gun). One possible, if partial, explanation for this discrepancy may be that rates of crime and violence affecting adolescents were higher in the inner city in 1995 than in California during our study period (2000-01). Because of this, our cohort may have been less likely to perceive a need to carry concealed firearms than did the 1995 urban cohort.

About half of the incidents involved shooting (for example, hunting or target practice) and, when the locale was known, the majority of unsupervised handling took place outside the respondent's home, and occurred when the adolescent was with friends. This finding has important implications for parents, who need to realize that making one's own home firearm-safe is not sufficient protection against adolescent's potentially injurious firearm related behaviors.

Consistent with previous work linking weapon carrying among children to the lack of parental monitoring and to otherwise poor relationships with parents, ${ }^{61}$ we found that unsupervised handling was more common among adolescents who reported that their parents knew little or nothing about their whereabouts in the afternoon.

Older age was associated with unsupervised handling in the bivariate analysis; however, because age is highly correlated with binge drinking and with smoking, both of which are strongly associated with unsupervised handling, age was no longer statistically related to gun handling behavior in multivariate analysis. The high negative correlation of smoking and binge drinking with Black race also explains why simple comparisons did not find that African Americans were significantly more likely than Whites to report unsupervised handling, while in the multivariate analyses, the odds of handling a firearms without adult supervision were twice as great for African American as for White adolescents.

In our study, three adolescents reported that their most recent unsupervised firearm handling involved handling a gun in self defense. These three adolescents constitute $20 \%$ of the 15 reported self defense gun uses by adolescents, whether or not they had adult permission to use the firearm (not shown); far fewer adolescents in this cohort report using a gun in self defense than having been threatened with a gun. ${ }^{56}$

Four adolescents reported that the gun was fired unintentionally in the most recent episode of unsupervised handling and one adolescent reported that a bullet fired unintentionally hit a bystander. We have no data on the number of unintentional shootings that occurred while a firearm was being used with adult knowledge or supervision.

One strength of the CHIS adolescent survey is its ability to capture adolescents who have left school. Fewer than $2 \%$ of the adolescents in the survey were not in school, but they were almost three times as likely to handle a gun without adult knowledge or supervision. The relationship between school and unsupervised handling did not hold in the multivariate analysis once smoking and binge drinking were taken into account. 
The CHIS survey has a variety of other strengths. It was designed to capture the diversity of California's population by administering the questionnaire in multiple languages. Survey questions were culturally reviewed, advance letters were sent in six languages to most of the potential sample, and interviewers trained in refusal conversions recontacted potential respondents who initially refused to participate.

In recent years general response rates to telephone surveys appear to have decreased. Caller ID, call blocking, cell phones, and other technological changes, along with an increase in marketing calls masked as scientific surveys, may have contributed to the reduction. In addition, approximately 5\% of households in California do not have a telephone and were, thus, not part of the survey. In the CHIS survey, although $84 \%$ of the adolescents contacted agreed to be interviewed, taking into account the dual layers of permission, the overall response rate was low. In addition, adolescents who engage in some risky behaviors may be more difficult to reach than adolescents who do not. The effect of this potential differential response rate on our findings is not known.

The survey has other limitations. Results come from only one state, and may not be generalizable. Data come from adolescent self reports, may be particularly subject to reporting bias such as self presentation bias, and were not externally corroborated by any other sources. Previous work using the CHIS survey found that a lower proportion of CHIS respondents reported smoking cigarettes, drinking alcohol, or using drugs than did respondents to the California Student Survey, a legislatively mandated survey of 7 th, 9 th, and 11 th grade students from a representative sample of public and private secondary schools in California. ${ }^{62}$ Whether responses about risk taking behavior around guns in our survey is similarly low is not known.

In addition, the definition of unsupervised gun handling was left to the respondent and the open ended descriptions given were usually short and often unclear. It is possible that some respondents may have interpreted the question "have you ever handled a gun without either adult supervision or knowledge" as requiring specific adult supervision or knowledge for every particular act of handling a firearm. Categories

\section{Key points}

- This study adds new information about firearm related experiences of adolescents by providing verbatim descriptions of the most recent episode of unsupervised firearm handling.

- One third of California adolescents report that they have handled a firearm; $5 \%$ report that they have done so without adult knowledge or supervision.

- Half of all unsupervised handling involved shooting, only $11 \%$ occurred in the respondent's home, and most occurred with friends.

- Male gender, living in a rural area, smoking, drinking, being the victim of a gun related threat, and having a gun in the home were each associated with unsupervised firearm handling.

- Unsupervised firearm handling by adolescents was more common among adolescents who reported that their parents knew little or nothing about their whereabouts in the afternoon.

- Parents should know that making their own home firearm safe is not sufficient protection against their child's potentially injurious firearm related behaviors. of the circumstances of unsupervised handling were created post hoc, after reading the short narratives, and up to $50 \%$ of incidents could not be categorized in each of our three taxonomies of what the adolescent was doing with the gun, where, and with whom. Lastly, correlates of unsupervised gun handling in our study cannot accurately be termed "risk factors" because of the cross sectional nature of the data and because the time periods for many of the variables were not identical. For example, the question on binge drinking asked about activities engaged in during the past 30 days, while the question on unsupervised handling asked about the entire life of the respondent.

Despite these limitations, our results indicate that unsupervised gun handling is associated with other risky behaviors-such as cigarette smoking and binge drinking. Unsupervised gun handling often involves shooting the gun, frequently occurs with friends away from the home, and is most typical in adolescents whose parents do not know their whereabouts in the afternoon.

\section{ACKNOWLEDGEMENTS}

We extend our thanks to everyone at the California Health Interview Survey and to the thousands of California adolescents who completed the survey along with their parents who gave permission for them to be interviewed. Particular thanks are owed to Susan B Sorenson who obtained funding for the research and who commented on drafts of the manuscript. Thanks also to Steven Lippmann who read all the descriptions and helped categorize the responses. This research was made possible by funding from the Joyce Foundation and the David and Lucile Packard Foundation. We are grateful for their support.

\section{Authors' affiliations}

M Miller, D Hemenway, Harvard School of Public Health, Boston

\section{REFERENCES}

1 Duggan M. More guns, more crime. Journal of Political Economy 2001; 109:1086-14

2 Gotsch K, Annest J, Mercy J, et al. Surveillance for fatal and nonfatal firearmrelated injuries-United States, 1993-1998. MMWR Morb Mortal Wkly Rep 2001;50:1-32

3 Shah S, Hoffman RE, Wake L, et al. Adolescent suicide and household access to firearms in Colorado: results of a case-control study. J Adolesc Health 2000;26:157-63.

4 Brent DA, Perper JA, Goldstein CE, et al. Risk factors for adolescent suicide. A comparison of adolescent suicide victims with suicidal inpatients. Arch Gen Psychiatry 1988;45:581-8.

5 Brent DA, Perper JA, Allman CJ, et al. The presence and accessibility of firearms in the homes of adolescent suicides. A case-control study. JAMA 1991;266:2989-95

6 Brent DA, Perper JA, Moritz G, et al. Firearms and adolescent suicide. A community case-control study. Am J Dis Child 1993;147:1066-71.

7 Brent DA, Perper JA, Moritz G, et al. Suicide in affectively ill adolescents: a case-control study. J Affect Disord 1994;31:193-202.

8 Brent DA, Perper J, Moritz G, et al. Suicide in adolescents with no apparent psychopathology. J Am Acad Child Adolesc Psychiatry 1993;32:494-500.

9 Kellermann AL, Rivara FP, Somes G, et al. Suicide in the home in relation to gun ownership. N Engl J Med 1992;327:467-72.

10 Cummings P, Koepsell TD, Grossman DC, et al. The association between the purchase of a handgun and homicide or suicide. Am J Public Health 1997;87:974-8.

11 Wintemute GJ, Parham CA, Beaumont JJ, et al. Mortality among recent purchasers of handguns. N Engl J Med 1999:341:1583-9.

12 Markush RE, Bartolucci AA. Firearms and suicide in the United States. Am J Public Health 1984;74:123-7.

13 Lester D. Firearm availability and the incidence of suicide and homicide. Acta Psychiatr Belg 1988:88:387-93.

14 Miller M, Azrael D, Hemenway D. Household firearm ownership and suicide rates in the United States. Epidemiology 2002;13:517-24.

15 Miller M, Azrael D, Hemenway D. Firearm availability and suicide, homicide, and unintentional firearm deaths among women. J Urban Health 2002;79:26-38

16 Miller M, Azrael D, Hemenway D. Firearm availability and unintentional firearm deaths, suicide, and homicide among 5-14 year olds. J Trauma 2002; 52:267-74

17 Hemenway D, Miller M. Association of rates of household handgun ownership, lifetime major depression, and serious suicidal thoughts with rates of suicide across US census regions. Inj Prev 2002;8:313-16.

18 Wiebe DJ. Homicide and suicide risks associated with firearms in the home: a national case-control study. Ann Emerg Med 2003;41:771-82. 
19 Wintemute GJ, Wright MA, Drake CM. Increased risk of intimate partner homicide among California women who purchase handguns. Ann Emerg Med 2003;41:281-3.

20 Miller M, Azrael D, Hemenway D. Rates of household firearm ownership and homicide across US regions and states, 1988-1997. Am J Public Health 2002;92:1988-93.

21 Hemenway D, Shinoda-Tagawa T, Miller M. Firearm availability and female homicide victimization rates among 25 populous high-income countries. J Am Med Womens Assoc 2002;57:100-4.

22 Lester $\mathbf{D}$. Firearm availability and the use of firearms for suicide and homicide. Percept Mot Skills 2000;91:998.

23 Hemenway D, Miller M. Firearm availability and homicide rates across 26 high-income countries. J Trauma 2000;49:985-8.

24 Kellermann AL. Guns and homicide in the home. N Engl J Med 1998:339:928-9.

25 Sacks JJ, Mercy JA, Ryan GW, et al. Guns in the home, homicide, and suicide. JAMA 1994;272:847-8.

26 Kellermann AL, Rivara FP, Rushforth NB, et al. Gun ownership as a risk factor for homicide in the home. N Engl J Med 1993:329:1084-91.

27 Killias $M$. International correlations between gun ownership and rates of homicide and suicide. CMAJ 1993;148:1721-5.

28 Miller M, Azrael D, Hemenway D. Firearm availability and unintentional firearm deaths. Accid Anal Prev 2001;33:477-84.

29 Wiebe DJ. Firearms in US homes as a risk factor for unintentional gunshot fatality. Accid Anal Prev 2003;35:711-16.

30 Grossman DC, Reay DT, Baker SA. Self-inflicted and unintentional firearm injuries among children and adolescents: the source of the firearm. Arch Pediatr Adolesc Med 1999;153:875-8.

31 Swahn MH, Hammig BJ, Ikeda RM. Prevalence of youth access to alcohol or a gun in the home. Inj Prev 2002;8:227-30.

32 Grunbaum JA, Kann L, Kinchen SA, et al. Youth risk behavior surveillanceUnited States, 2001. J Sch Health 2002;72:313-28.

33 Hardy MS, Armstrong FD, Martin BL, et al. A firearm safety program for children: they just can't say no. J Dev Behav Pediatr 1996;17:216-21.

34 Hardy MS. Teaching firearm safety to children: failure of a program. J Dev Behav Pediatr 2002;23:71-6.

35 Jackman GA, Farah MM, Kellermann AL, et al. Seeing is believing: what do boys do when they find a real gun? Pediatrics 2001;107:1247-50.

36 Williams SS, Mulhall PF, Reis JS, et al. Adolescents carrying handguns and taking them to school: psychosocial correlates among public school students in Illinois. J Adolesc 2002;25:551-67.

37 Wilcox $\mathbf{P}$, Clayton R. A multilevel analysis of school-based weapon possession. Justice Quarterly $2001 ; 18: 509-41$

38 Vaughan RD, McCarthy JF, Armstrong B, et al. Carrying and using weapons: a survey of minority junior high school students in New York City. Am J Public Health 1996;86:568-72.

39 Smith $\mathbf{M}$. Sources of firearm acquisition among a sample of inner-city youths: research results and policy implications. Journal of Criminal Justice 1997;24:361-7.

40 Sheley JF. Drugs and guns among inner-city high school students. J Drug Educ 1994;24:303-21.

41 Sheley JF, Brewer VE. Possession and carrying of firearms among suburban youth. Public Health Rep 1995;110:18-26.
42 Kulig J, Valentine J, Griffith J, et al. Predictive model of weapon carrying among urban high school students: results and validation. J Adolesc Health 1998;22:312-19.

43 Kahn DJ, Kazimi MM, Mulvihill MN. Attitudes of New York City high schoo students regarding firearm violence. Pediatrics $2001 ; 107: 1125-32$.

44 Lowry R, Powell KE, Kann L, et al. Weapon-carrying, physical fighting, and fight-related injury among US adolescents. Am J Prev Med 1998;14:122-9.

45 Bailey SL, Flewelling RL, Rosenbaum DP. Characteristics of students who bring weapons to school. J Adolesc Health 1997;20:261-70.

46 Callahan CM, Rivara FP. Urban high school youth and handguns. A schoolbased survey. JAMA 1992;267:3038-42.

47 Webster DW, Freed LH, Frattaroli S, et al. How delinquent youths acquire guns: initial versus most recent gun acquisitions. J Urban Health 2002;79:60-9.

48 Freed LH, Webster DW, Longwell JJ, et al. Factors preventing gun acquisition and carrying among incarcerated adolescent males. Arch Pediatr Adolesc Med 2001;155:335-41.

49 Snyder H, Sickmund M, Poe-Yamagata E. Juvenile offenders and victims: update on violence. Washington, DC: US Department of Justice, Office of Juvenile Justice and Delinquency Prevention, 1996.

50 Callahan CM, Rivara FP, Farrow JA. Youth in detention and handguns. $J$ Adolesc Health 1993;14:350-5.

51 Sheley JF, McGee ZT, Wright JD. Gun-related violence in and around innercity schools. Am J Dis Child 1992;146:677-82.

52 Webster DW, Gainer PS, Champion HR. Weapon carrying among inner-city junior high school students: defensive behavior vs aggressive delinquency. Am J Public Health 1993;83:1604-8.

53 Hemenway D P-SD, Bergstein J, et al. Gun carrying among adolescents. J Law Contemp Problems 1996.

54 Bergstein JM, Hemenway D, Kennedy B, et al. Guns in young hands: a survey of urban teenagers' attitudes and behaviors related to handgun violence. J Trauma 1996;41:794-8

55 UCLA Center for Health Policy Research. Survey methdology, California Health Interview Survey. Available at: http://www.chis.ucla.edu/ chis_methods.html.

56 Hemenway D, Miller M. Gun threats against and self-defense gun use by California adolescents. Arch Pediatr Adolesc Med 2004;158:395-400.

57 Miller M, Hemenway D, Wechsler H. Guns and gun threats at college. J Am Coll Health 2002:51:57-65.

58 Brent DA, Perper JA, Allman CJ. Alcohol, firearms, and suicide among youth Temporal trends in Allegheny County, Pennsylvania, 1960 to 1983. JAMA 1987;257:3369-72.

59 Nelson DE, Grant-Worley JA, Powell K, et al. Population estimates of household firearm storage practices and firearm carrying in Oregon. JAMA 1996;275:1744-8.

60 Orpinas PK, Basen-Engquist K, Grunbaum JA, et al. The co-morbidity of violence-related behaviors with health-risk behaviors in a population of high school students. J Adolesc Health 1995;16:216-25.

61 Orpinas P, Murray N, Kelder S. Parental influences on students' aggressive behaviors and weapon carrying. Health Educ Behav 1999;26:774-87.

62 Sorenson S, Vittes K. Adolescents and firearms: a statewide survey. Am J Public Health (in press). 